\title{
Kondisi Fisik Mahasiswa Prodi Pendidikan Jasmani, Kesehatan dan Rekreasi Fakultas Ilmu Keolahragaan
}

\author{
M. Rifki Zainul Rochman*, Siti Nurrochmah \\ Universitas Negeri Malang, Jl. Semarang No. 5 Malang, Jawa Timur, Indonesia \\ *Penulis korespondensi, Surel: rifkizainul86@gmail.com
}

Paper received: 31-9-2021; revised: 14-9-2021; accepted: 21-9-2021

\begin{abstract}
This study aims to describe and assess the level of ability of the physical condition students of the Physical Education, Health and Recreation (PJKR) class of 2018 off. B Faculty of Sport Science, State University of Malang, the results of data analysis of the 20 meter running speed test are 82.61 percent in the "enough" category, the agility T-test is 78.26 percent in the "enough" category, the zig zag agility test 78.26 percent for the "enough" category. , the muscle explosive power test of the upright jumping leg was 60.87 percent in the "good" category, the muscle explosive power test of the jumping leg of the frog was 60.87 percent in the "good" category, the muscle explosive power test of the arm in throwing the basketball without the prefix 54.35 percent was in the "enough" category, the body flexibility test 58.70 percent in the "good" category, the sit and reach body flexibility test of 54.35 percent in the "sufficient" category, and the static back-up body flexibility test of 54.35 percent including the "good" category. The conclusion of this study is the ability of the physical condition of the students of the Physical Education, Health and Recreation (PJKR) study program class of 2018 off. B, Faculty of Sport Science, State University of Malang, is in the moderate category.
\end{abstract}

Keywords: physical condition; practical course learning; PJKR study program students

\begin{abstract}
Abstrak
Penelitian ini bertujuan untuk mendeskripsikan dan mengkaji tingkat kemampuan kondisi fisik mahasiswa prodi Pendidikan Jasmani, Kesehatan dan Rekreasi (PJKR) angkatan tahun 2018 off. B Fakultas Ilmu Keolahragaan Universitas Negeri Malang diperoleh hasil analisis data tes kecepatan lari 20 meter 82,61 persen kategori “cukup", tes kelincahan T-test 78,26 persen kategori “cukup", tes kelincahan zigzag 78,26 persen kategori "cukup", tes daya ledak otot tungkai loncat tegak 60,87 persen kategori "baik", tes daya ledak otot tungkai loncat katak 60,87 persen kategori "baik", tes daya ledak otot lengan lempar bolabasket tanpa awalan 54,35 persen kategori "cukup", tes kelentukan tubuh kayang 58,70 persen kategori "baik", tes kelentukan tubuh sit and reach 54,35 persen kategori "cukup", dan tes kelentukan tubuh back-up tubuh statis 54,35 persen termasuk kategori "baik". Kesimpulan dari penelitian ini adalah kemampuan kondisi fisik mahasiswa prodi Pendidikan Jasmani, Kesehatan dan Rekreasi (PJKR) angkatan tahun 2018 off. B Fakultas Ilmu Keolahragaan Universitas Negeri Malang termasuk dalam kategori cukup.
\end{abstract}

Kata kunci: kondisi fisik; pembelajaran matakuliah praktik; mahasiswa prodi PJKR

\section{Pendahuluan}

Belajar merupakan rangkaian aktivitas yang dilakukan oleh peserta didik dalam upaya mengubah perilaku yang dilakukan secara sadar melalui interaksi dengan lingkungan (Anitah, 2014). Pembelajaran membentuk aktivitas yang meliputi aktivitas terbagi menjadi dua sifat yaitu psikologis maupun fisiologis (Darmawan, 2012). Melalui aktivitas jasmani/fisik seperti olahraga, akan berdampak pada keadaan kondisi fisik yang dimiliki setiap individu. Mahasiswa prodi PJKR tidak dapat terlepas dari aktivitas fisik, dan aktivitas fisik tersebut hampir tiap hari dijalani oleh mahasiswa prodi PJKR. 
Belajar gerak merupakan suatu fenomena manusia yang mempelajari atau berusaha menguasai gerakan-gerakan tubuh untuk meningkatkan keterampilan gerak tubuhnya (Lumintuarso, 2013). Belajar gerak melibatkan kemampuan fisik secara optimal untuk melakukan berbagai aktivitas gerak, hal ini mengakibatkan kondisi peserta didik ketika belajar gerak dapat mengalami kelelahan. Untuk menunjang semua aktivitas gerak dibutuhkan keadaan kemampuan kondisi fisik yang berhubungan aspek fisiologis dan aspek gerak/keterampilan. Seseorang akan mampu melakukan berbagai keterampilan gerak seperti bentuk teknik dasar dan lanjutan pada pembelajaran gerak dengan baik, jika tiap individu memiliki berbagai kemampuan seperti kemampuan fisik yang baik (Wiarto, 2015).

Kemampuan kondisi fisik adalah kemampuan fisik seseorang untuk mendukung jalannya aktivitas fisik sehingga mampu memfungsikan organ-organ tubuh untuk mendukung aktivitas psikomotor (Rahyubi, 2014). Tiap individu, termasuk mahasiswa Prodi PJKR, penting memiliki kondisi fisik yang baik untuk mendukung setiap kinerja dalam melakukan pembelajaran gerak atau latihan-latihan ataupun aktivitas fisik lainnya yang dilakukan tiap hari.

Rahyubi (2017) berpendapat bahwa unsur kemampuan pada setiap individu bisa berfungsi dengan baik, jika menghasilkan gerakan yang efektif dan efisien. Berarti untuk mencapai efisiensi gerak diperlukan beberapa kemampuan, seperti kemampuan fisik, dan kemampuan mental. Diantara macam kemampuan tersebut, peneliti mengkaji salah satu kemampuan yaitu kemampuan atau keadaan kondisi fisik. Siedentop (2009) berpendapat bahwa untuk melakukan berbagai aktivitas fisik dalam pembelajaran pendidikan jasmani dan olahraga, peserta didik/mahasiswa seharusnya memiliki motor performance fitness (kinerja kebugaran gerak) yang baik seperti unsur kelincahan, keseimbangan, daya ledak, waktu reaksi, kecepatan dan koordinasi. Irawan (2014) melaporkan hasil penelitiannya bahwa Ada hubungan kelentukan togok, daya ledak otot tungkai dan kekuatan otot tungkai terhadap servis slice. Wiarto (2015) berpendapat bahwa modal kemampuan fisik sangat penting dan dibutuhkan dalam pembelajaran gerak untuk memperoleh keterampilan atau ketangkasan gerak yang optimal dan memuaskan. Modal fisik yang dimaksud adalah kemampuan keseimbangan, daya tahan, kekuatan, kelincahan dan kelentukan. Adindra et al. (2016) latihan kelentukan dan kelincahan untuk meningkatkan keterampilan dribel dalam hoki. Berarti latihan kelincahan dan kelentukan dapat meningkatkan keterampilan dribel dalam olahraga hoki.

Bompa \& Buzzichelli (2015) berpendapat bahwa kemampuan biomotor (kemampuan fisik) yang mempunyai peranan penting dalam kinerja olahraga dan dibutuhkan oleh berbagai jenis olahraga serta memberikan sumbangan yang signifikan pada kinerja adalah komponen kekuatan, daya tahan, kecepatan, kelentukan, dan koordinasi. Rahyubi (2017) menjelaskan bahwa kemampuan kondisi yang dibutuhkan dalam pembelajaran gerak meliputi kemampuan fisik unsur stabilitas dan keseimbangan, daya tahan, kekuatan, kelincahan dan kelentukan tubuh.

Dalam kajian ini peneliti mengkaji komponen kelincahan, kelentukan, kecepatan dan daya ledak (Siedentop, 2009), karena pada pembelajaran/perkuliahan di semester IV (genap) matakuliah praktik yang disajikan meliputi matakuliah pembelajaran bolabasket, bolavoli, sepakbola, tenismeja, bulutangkis. Siedentop (2009) berpendapat bahwa komponen kelincahan, keseimbangan, daya ledak, waktu reaksi, kecepatan dan koordinasi dikatakan 
sebagai motor performance fitness (kebugaran kinerja gerak) mempunyai peranan penting untuk dapat melakukan keterampilan gerak yang baik, karena komponen tersebut menunjang unjuk kerja (performance) keterampilan dalam olahraga, seperti dribel bolabasket, keterampilan dalam permainan voli, senam dan aktivitas gerak lainnya.

Kecepatan adalah kemampuan melakukan gerakan dalam periode waktu yang pendek (Harsono, 2015). Bompa \& Buzzichelli (2015) menjelaskan bahwa speed is the ability to perform a movement in a short period of time, maksudnya kecepatan adalah kemampuan melakukan gerakan dalam jangka waktu yang pendek/cepat. Fenanlampir \& Faruq (2015) kelincahan adalah semua aktivitas yang membutuhkan kecepatan perubahan posisi tubuh dan bagian-bagiannya dalam waktu yang cepat.

Daya ledak otot berhubungan dengan kemampuan tubuh untuk melawan tahanan/beban dengan menggunakan gerakan yang sangat cepat (Nurrochmah, 2016). (Harsono, 2017a) berpendapat bahwa kelentukan adalah kemampuan seseorang untuk melakukan gerakan pada ruang gerak persendian. (Betul, 2015) mengatakan bahwa kemampuan fisik merupakan salah satu faktor utama yang berfungsi untuk melakukan gerakan. Agar seseorang mampu melakukan gerakan yang efektif dan efisien, seharusnya didukung oleh kemampuan kondisi fisik yang baik. Untuk mengetahui kemampuan kondisi yang baik penting dilakukan pengukuran bentuk tes terhadap komponen-komponen kondisi fisik tersebut.

Hasil survei awal saat melakukan observasi peneliti menjumpai di lapangan ketika pembelajaran matakuliah praktik tertentu tampilan unjuk kerja mahasiswa prodi PJKR kurang optimal seperti tidak adanya unsur kekuatan atau power dari dalam tubuh untuk menggerakkan alat atau membawa tubuh untuk bergerak. Hal ini diprediksi bahwa mahasiswa tersebut keadaan kemampuan fisik menunjukkan kurang baik. Terkait dengan kondisi fisik tersebut, terdapat penelitian terdahulu yang dilakukan Meirawati \& Nurrochmah (2020) tentang kondisi fisik Atlet PPLP Jatim Cabor Atletik. Yudistian (2018) melakukan penelitian tentang tingkat kondisi fisik mahasiswa jurusan Ilmu Keolahragaan angkatan masuk tahun 2016 Universitas Negeri Malang. Litardiansyah \& Hariyanto (2020) tentang survei kondisi fisik peserta ekstrakurikuler futsal putra dan putri Sekolah Menengah Atas.

Berdasar hasil pengamatan yang dilakukan peneliti dalam kegiatan pembelajaran, yang menjadi masalah yang diteliti yaitu tentang kemampuan kondisi fisik mahasiswa Prodi PJKRFIK-UM, sedangkan untuk mengetahui dengan tepat keadaan kemampuan fisik mahasiswa PJKR khususnya angkatan 2018, maka penting dilakukan pengukuran tentang kemampuan fisik tertentu yang dominan banyak digunakan pada aktivitas jasmani khusus matakuliah praktik melalui penelitian.

Oleh karena itu, telah dilakukan penelitian tentang kondisi fisik berjudul "Kemampuan Kondisi Fisik Mahasiswa Prodi Pendidikan Jasmani, Kesehatan dan Rekreasi Angkatan Tahun 2018 off. B Fakultas Ilmu Keolahragaan Universitas Negeri Malang". Tujuan penelitian ini adalah untuk mendeskripsikan dan mengkaji tingkat kemampuan kondisi fisik yang mencakup komponen kecepatan gerak, kelincahan gerak, daya ledak otot, dan kelentukan tubuh pada mahasiswa prodi Pendidikan Jasmani, Kesehatan dan Rekreasi (PJKR) angkatan tahun 2018 off. B Fakultas Ilmu Keolahragaan Universitas Negeri Malang. 


\section{Metode}

Penelitian ini menggunakan rancangan survei bentuk deskriptif kuantitatif, pendekatan berupa metode deskriptif (Nazir, 2017). Variabel yang diteliti adalah kemampuan kondisi fisik yang meliputi komponen kecepatan gerak, kelincahan gerak, daya ledak otot, dan kelentukan tubuh. Subjek penelitian yaitu mahasiswa prodi PJKR angkatan tahun 2018 off. B FIK-UM berjumlah 46 orang. Penelitian menggunakan instrumen tes kondisi fisik, dan non tes bentuk observasi dan pengumpulan data menggunakan teknik pengukuran bentuk tes dan observasi. Data dianalisis menggunakan statistika deskriptif kuantitatif berupa tendensi sentral dan variabilita.

\section{Hasil dan Pembahasan}

\subsection{Hasil}

Hasil analisis data yang telah diperoleh seluruh mahasiswa prodi PJKR angkatan tahun 2018 off. B, FIK-UM dengan norma tes kecepatan gerak dominan pada kriteria tidak baik berjumlah 38 orang $(82,61 \%)$ dari 46 orang dan KV 16,95\% (data menyebar dalam suatu distribusi). Kemampuan kelincahan bentuk T-test dominan pada kriteria tidak baik berjumlah 36 orang $(78,26 \%)$ dan KV 10,68\%. Hasil tes kelincahan lari zigzag dominan pada kriteria tidak baik 36 orang $(78,26 \%)$ dari 46 orang, dan KV diperoleh 12,40\%, berarti menyebar dalam suatu distribusi.

Hasil tes daya ledak otot tungkai tes loncat tegak dominan pada kriteria baik 28 orang $(60,87 \%)$ dan KV 18,74\%. Tes daya ledak otot tungkai tes loncat katak dominan kriteria baikbaik sekali berjumlah 28 orang $(60,87 \%)$ dan KV 12,62\% berarti data menyebar. Hasil daya ledak otot lengan bentuk tes lempar bolabasket tanpa awalan, dominan pada kriteria tidak baik 25 orang $(54,35 \%)$ dan KV diperoleh hasil $12,44 \%$ data menyebar. Hasil kelentukan tubuh tes kayang dominan kriteria baik terdapat 27 orang (58,70\%) dari 46 orang dan KV diperoleh hasil 10,91\%. Tes sit and reach pada kriteria tidak baik 25 orang (54,35\%) dan KV diperoleh 35,19\% data menyebar. Hasil tes back-up dominan pada kriteria baik 25 orang $(54,35 \%)$ dari 46 orang dan KV diperoleh hasil 7,24\% data cenderung memusat.

Berdasarkan uraian di atas, tingkat kemampuan kondisi fisik mahasiswa prodi PJKR angkatan tahun 2018 off. B FIK-UM kemampuan kondisi fisik dominan termasuk dalam kriteria "cukup" (norma dibuat berdasarkan data hasil tes dari mahasiswa prodi PJKR angkatan tahun 2018 off. B FIK-UM.

\subsection{Pembahasan}

Dalam penelitian ini peneliti mendeskripsikan dan mengkaji informasi tingkat kemampuan kondisi fisik yang meliputi komponen kecepatan gerak, kelincahan gerak, daya ledak otot tungkai dan lengan, dan kelentukan tubuh pada mahasiswa angkatan tahun 2018 off. B Prodi PJKR FIK-UM, maka untuk mencapai tujuan tersebut dilakukan pengumpulan data menggunakan teknik dokumentasi dan observasi bentuk tes yang dilengkapi petunjuk teknis pelaksanaan tes. Komponen kondisi fisik untuk menunjang pembelajaran gerak yang dipilih untuk diteliti, hal ini merujuk Siedentop (2009) berpendapat bahwa untuk melakukan berbagai aktivitas fisik dalam pembelajaran pendidikan jasmani dan olahraga, peserta didik/mahasiswa seharusnya memiliki motor performance fitness (kebugaran kinerja gerak) yang baik seperti unsur kelincahan gerak, keseimbangan, daya ledak, waktu reaksi, kecepatan 
dan koordinasi. Bompa \& Buzzichelli (2015) mengatakan bahwa komponen biomotor yang penting diperhatikan dalam kinerja fisik adalah komponen kekuatan, daya tahan, kelentukan, koordinasi, kecepatan dan daya ledak otot.

Merujuk pendapat beberapa ahli tersebut di atas, dalam penelitian ini peneliti meneliti komponen yang banyak dibutuhkan dalam pembelajaran gerak yaitu komponen kecepatan gerak, kelincahan gerak, daya ledak otot tungkai dan lengan, dan kelentukan tubuh.

Hasil analisis data komponen kecepatan gerak menggunakan tes lari 20 m pada mahasiswa angkatan tahun 2018 off. B Prodi PJKR FIK-UM dominan berada pada kriteria cukup, beberapa tes kelincahan berada pada kriteria cukup, komponen daya ledak otot tungkai dominan berada pada kriteria baik. Komponen daya ledak otot lengan dominan kriteria cukup, hasil tes kayang cenderung berada pada kriteria baik, hasil tes sit and reach cenderung kriteria cukup, komponen kelentukan tubuh menggunakan tes back-up tubuh statis cenderung berada pada kriteria baik.

Secara keseluruhan hasil tes komponen kemampuan kondisi fisik pada mahasiswa prodi PJKR angkatan tahun 2018 off. B FIK-UM berjumlah 46 orang hasil tes yang diperoleh dari komponen-komponen yang diteliti, dominan menunjukkan berada pada kriteria cukup (di bawah kriteria baik sama dengan kriteria tidak baik). Norma yang digunakan berasal norma yang dibuat merujuk data hasil tes dari mahasiswa angkatan tahun 2018 off. B Prodi PJKR FIKUM. Untuk memperoleh komponen fisik yang baik penting melakukan latihan-latihan yang teratur (Hidayat, 2014). Cahyono et al. (2017) hasil penelitian dilaporkan bahwa latihan ladder drill lebih baik secara signifikan terhadap peningkatan kecepatan lari dibandingkan dengan latihan konvensional untuk peserta kegiatan ekstrakurikuler sepakbola SMA Negeri 1 Pagak Kabupaten Malang.

Penyebab hasil analisis data secara keseluruhan dominan cenderung pada kriteria cukup (di bawah kriteria baik sama dengan kriteria tidak baik), jika dikaji sangat komplek banyak faktor yang mempengaruhi aktivitas gerak adalah faktor fisik, termasuk keadaan kemampuan kondisi fisik, antropometri tubuh, status kesehatan seperti kelelahan berpengaruh pada unjuk kerja keterampilan passing basket (Canli et al., 2018). Faktor lain seperti psikhis, faktor tingkat kematangan, perhatian dan minat, tingkat kecerdasan, bakat, kepribadian, motivasi, tingkat kebugaran jasmani seperti tingkat kelelahan (Kiram, 2019). Peneliti amati ketika pelaksanaan tes, dapat identifikasikan penyebab hasil tes berada pada kriteria sedang/cukup adalah faktor (a) usia, (b) jenis kelamin, (c) antropometri tubuh seperti tinggi badan dan berat badan, (d) tingkat kebugaran jasmani seperti faktor kelelahan, (e) status kesehatan, (f) aktivitas gerak sebelumnya, (g) waktu pelaksanaan tes, (h) koordinasi gerak (i) kondisi fisik, (j) persepsi/daya tangkap terhadap rangkaian tes dan (k) dan kemampuan gerak reflek untuk melakukan rangkaian gerakan tes (Komarudin, 2016).

Lumintuarso (2013) berpendapat bahwa belajar gerak merupakan suatu fenomena manusia yang mempelajari atau berusaha menguasai gerakan-gerakan tubuh untuk meningkatkan keterampilan gerak tubuhnya. Belajar keterampilan gerak adalah belajar yang diwujudkan melalui respon-respon dari otot berupa gerakan-gerakan tubuh (Rusman et al., 2012). Untuk belajar gerak/belajar keterampilan motorik membutuhkan komponen kebugaran kinerja gerak seperti unsur kelincahan, kecepatan, kelentukan, daya ledak otot termasuk koordinasi gerak. Harsono (2017) modal kemampuan fisik sangat penting dimiliki dan ditingkatkan bagi setiap orang yang berkecimpung dalam aktivitas fisik seperti belajar 
gerak. Corbin et al. (2011) kemampuan fisik termasuk komponen kebugaran kinerja gerak dibutuhkan dalam pembelajaran gerak untuk memperoleh penguasaan keterampilan atau ketangkasan gerak adalah komponen kebugaran kinerja gerak seperti kelincahan, kecepatan, daya ledak dan koordinasi Komponen tersebut penting ditingkatkan Mubarok \& Mudzakir (2020) kesimpulan hasil penelitian dilaporkan bahwa latihan kelincahan small sided games dengan metode interval dan repetisi memberikan pengaruh terhadap peningkatan keterampilan dribbling pemain sepakbola.

Modal fisik seperti keseimbangan, daya tahan, kekuatan, kelincahan dan kelentukan dibutuhkan dalam belajar keterampilan seperti keterampilan dribel sepakbola sehingga penting ditingkatkan melalui latihan fisik (Sidik et al., 2019). Rahyubi (2017) mengatakan bahwa kemampuan kondisi yang dibutuhkan dalam pembelajaran gerak meliputi kemampuan fisik stabilitas dan keseimbangan, daya tahan, kekuatan, kelincahan dan kelentukan tubuh. Untuk menguasai beberapa keterampilan gerak, dibutuhkan keberadaan kemampuan kondisi fisik yang berhubungan dengan keterampilan gerak (Kiram, 2019).

Irawan (2014) kesimpulan hasil penelitian dilaporkan bahwa ada hubungan antara kelentukan togok, daya ledak otot tungkai dan kekuatan otot tungkai terhadap servis slice dalam olahraga tenis lapangan. Berarti komponen kondisi fisik tersebut turut menentukan ketercapaian dalam keterampilan olahraga.

Darmawan (2012) mengatakan bahwa belajar merupakan aktivitas yang dilakukan secara psikologis maupun fisiologis. Aktivitas yang bersifat psikologis yaitu aktivitas bentuk proses mental misalnya aktivitas yang berhubungan dengan aktivitas berfikir, dan aktivitas yang berhubungan dengan aktivitas fisiologis berupa proses penerapan atau praktik, misalnya melakukan latihan-latihan, atau kegiatan praktik seperti praktik berbagai macam tes dalam pendidikan jasmani dan keolahragaan. Melalui latihan, pembelajaran materi praktik/gerak agar berbagai keterampilan teknik dapat dikuasai oleh setiap individu (Rahyubi, 2012). Chandrakumar \& Ramesh (2015: 527-529) melaporkan hasil penelitian bahwa latihan leader dan SAQ dapat memperbaiki unsur kelincahan dan kecepatan pada pemain olahraga badminton. Hal ini didukung dengan hukum belajar berupa hukum latihan yang dikemukakan oleh Thorndike (Wiarto, 2015) bahwa pembelajaran gerak, semakin banyak peserta didik melakukan latihan-latihan atau pengulangan-pengulangan, maka keterampilan yang dipelajari semakin baik dan gerakannya semakin natural. Meironi \& Oktaviani, (2018) laporan hasil penelitian disimpulkan bahwa latihan side-to-side shuffle jump berpengaruh terhadap peningkatan daya ledak otot tungkai mahasiswa. Jadi latihan teratur dapat meningkatkan komponen kondisi fisik yang dibutuhkan.

Kaitannya dengan ulangan atau latihan tersebut, Suyono \& Hariyanto (2016) berpendapat bahwa dalam kegiatan belajar terdapat prinsip umum belajar. Keberhasilan belajar dipengaruhi oleh beberapa faktor antara lain faktor lingkungan, tingkat kematangan, dan keaktifan individu secara optimal dalam kegiatan belajar. Teori belajar berupa the law of operant conditioning dari Skinner (Suyono \& Hariyanto, 2016) terkait dengan latihan atau pengulangan hubungannya teori tersebut yaitu jika timbulnya perilaku diiringi dengan stimulus penguat, maka kekuatan perilaku tersebut akan meningkat. Artinya bahwa jika keterampilan gerak yang diperoleh dari pembelajaran diikuti dengan latihan-latihan atau pengulangan-pengulangan, maka hasil pembelajaran keterampilan gerak akan mengalami peningkatan. Jadi jika menghendaki hasil belajar meningkat, maka dibutuhkan latihan-latihan 
atau pengulangan-pengulangan secara teratur sebagai stimulus respon yang dihasilkan akan memberi peningkatan hasil yang diperoleh.

Dengan demikian berarti agar kemampuan kondisi fisik berada pada kriteria baik, melakukan latihan adalah penting. Latihan akan berhasil apabila diikuti dengan penerapan prinsip-prinsip latihan secara tepat. Pada kajian ini yaitu survei tentang jenis kemampuan fisik yang digunakan dalam pembelajaran (bukan pelatihan), maka prinsip latihan diperlukan adalah prinsip latihan kaitannya dengan pembelajaran.

\section{Simpulan}

Berdasarkan hasil penelitian yang bertujuan untuk mendeskripsikan dan mengkaji tingkat kemampuan kondisi fisik pada mahasiswa prodi Pendidikan Jasmani, Kesehatan dan Rekreasi (PJKR) angkatan tahun 2018 off. B Fakultas Ilmu Keolahragaan Universitas Negeri Malang dengan jumlah sampel 46 orang, maka hasil penelitian dapat disimpulkan bahwa kemampuan kondisi fisik komponen kecepatan gerak termasuk kategori "cukup", komponen kelincahan gerak termasuk kategori "cukup", komponen daya ledak otot tungkai termasuk kategori "baik", komponen daya ledak otot lengan termasuk kategori "cukup", dan komponen kelentukan tubuh termasuk kategori "baik". Berdasarkan hasil penelitian yang telah dilakukan pada mahasiswa prodi Pendidikan Jasmani, Kesehatan, dan Rekreasi (PJKR) angkatan tahun 2018 off. B Fakultas Ilmu Keolahragaan Universitas Negeri Malang, peneliti menyarankan pada waktu pelaksanaan pembelajaran matakuliah praktik lebih mengoptimalkan proses pemanasan untuk menunjang kemampuan kondisi fisik, yang khususnya pada komponen kecepatan gerak, kelincahan gerak, daya ledak otot tungkai dan lengan, dan kelentukan tubuh.

\section{Daftar Rujukan}

Adindra, Rahayu, S., \& Sulaiman. (2016). Kelentukan Togok Dan Latihan Kelincahan Meningkatkan Kemampuan Dribble Pada Pemain Hoki Pemula. Journal of Physical Education and Sport, 5(1), 47-52.

Anitah, S. W. (2014). Strategi Pembelajaran di SD. Universitas Terbuka.

Betul, B. (2015). The effects of basketball basic skills training on gross motor skills development of female children. Educational Research and Reviews, 10(5), 648-653. https://doi.org/10.5897/err2014.2020

Bompa, T., \& Buzzichelli, C. A. (2015). Periodization Training for Sports. Human Kinetics.

Cahyono, I. ., Sugiarto, T., \& Amiq, F. (2017). Pengaruh Latihan Ladder Drill Terhadap Peningkatan Kecepatan Lari Peserta Ekstrakurikuler Sepakbola SMA. Gelanggang Pendidikan Jasmani Indonesia, 1(2), 282-290.

Canl, U., Ari, Y., \& Özmutlu, İ. (2018). The Effects of Morphological Structure and Fatigue on the Passing Skill in Pre-Pubescent Basketball Players. Journal of Education and Training Studies, 6(12), 37-43. https://doi.org/10.11114/jets.v6i12a.3921

Chandrakumar, N., \& Ramesh, C. (2015). Effect of ladder drill and SAQ training on speed and agility among sports club badminton players. International Journal of Applied Research, 1(2), 527-529.

Corbin, C. B., Welk, G. J., \& Corbin, W. R. (2011). Consepts of Fitness and Wellness. Mc Graw Hill.

Darmawan, D. (2012). Inovasi Pendidikan. Remaja Rosdakarya.

Fenanlampir, A., \& Faruq, M. M. (2015). Tes dan Pengukuran dalam Olahraga. Andi Offset.

Harsono. (2015). Periodisasi Program Pelatihan. Remaja Rosdakarya.

Harsono. (2017a). Kepelatihan Olahraga. Remaja Rosdakarya.

Harsono. (2017b). Periodisasi Program Pelatihan. Remaja Rosdakarya.

Hidayat, S. (2014). Pelatihan Olahraga. Teori dan methologi. Graha Ilmu.

Irawan, R. (2014). Hubungan Kelentukan Togok, Daya Ledak Otot Tungkai, Dan Kekuatan Otot Tungkai Terhadap Servis Slice Tenis Lapangan. Journal of Physical Education, Health and Sport, 1(2), 118-124. 
Kiram, Y. (2019). Belajar Keterampilan Motorik. Kencana.

Komarudin. (2016). Penilaian Hasil Belajar Pendidikan Jasmani dan Olahraga. Remaja Rosdakarya.

Litardiansyah, B.A. \& Hariyanto, E. 2020. Survei Kondisi Fisik Peserta Ekstrakurikuler Futsal Putra dan Putri Sekolah Menengah Atas. Sport Science and Health, 2(6), 331-339.

Lumintuarso, R. (2013). Pembinaan Multilateral Bagi Atlet Pemula. UNY Press.

Meirawati, N., \& Nurrochmah, S. (2020). Kemampuan Kecepatan Gerak Dan Daya Ledak Otot Siswa Pplp Jatim Di Kediri Cabang Olahraga Atletik. Gelanggang Pendidikan Jasmani Indonesia, 4(1), 28-35.

Meironi, A., \& Oktaviani, L. (2018). Pengaruh Latihan Side-To-Side Shuffle Jump Terhadap Peningkatan Daya Ledak Otot Tungkai Mahasiswa. Gelanggang Pendidikan Jasmani Indonesia, 2(2), 82-86.

Mubarok, M. ., \& Mudzakir, D. . (2020). Pengaruh Latihan Small Sided Games Terhadap Peningkatan Keterampilan Dribbling Pemain Sepakbola. Jurnal Pendidikan Olahraga, 9(1), 28-40.

Nazir, M. (2017). Metode Penelitian. Ghalia Indonesia.

Nurrochmah, S. (2016). Tes dan Pengukuran dalam Pendidikan Jasmani dan Keolahragaan. UM Press.

Rahyubi, H. (2012). Teori-Teori Belajar dan Aplikasi Pembelajaran Motorik. Deskriptip dan Tinajuan Kritis. Nusa Media.

Rahyubi, H. (2014). Teori-Teori Belajar dan Aplikasi Pembelajaran Motorik. Deskripsi dan Tinjauan Kritis. Nusa Media.

Rahyubi, H. (2017). Teori-Teori Belajar dan Aplikasi Pembelaaran Motorik. Deskripsi dan Tinjauan Kritis. Nusa Media.

Rusman, Kurniawan, D., \& Riyana, C. (2012). Pembelajaran Berbasis Teknologi Informasi dan Komunikasi. Mengembangkan Profesionalitas Guru. Rajawali Press.

Sidik, D. ., Pasurnay, P. ., \& Afari, L. (2019). Pelatihan Kondisi Fisik. Remaja Rosdakarya.

Siedentop. (2009). Introduction to Physical Education, Fitness and Sport. Mc Graw Hill

Suyono, \& Hariyanto. (2016). Belajar dan Pembelajaran. Teori dan Konsep Dasar. Remaja Rosdakarya.

Wiarto, G. (2015). Inovasi Pembelajaran dalam Pendidikan Jasmani. Laksitas.

Yudistian, R. 2018. Survei Tingkat Kondisi Fisik Mahasiswa Jurusan Ilmu Keolahragaan Angkatan Masuk Tahun 2016 Universitas Negeri Malang. Skripsi. Tidak Diterbitkan. Malang: Universitas Negeri Malang. 